\title{
Synaptic Connections of Aromatase Circuits in the Medial Amygdala Are Sex Specific
}

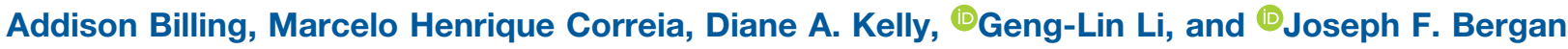

https://doi.org/10.1523/ENEURO.0489-19.2020

Neuroscience and Behavior Program, Department of Psychological and Brain Sciences, University of Massachusetts, Amherst, Amherst, Massachusetts 01003

\begin{abstract}
The brains of male and female mice are shaped by genetics and hormones during development. The enzyme aromatase helps establish sex differences in social behaviors and in the neural circuits that produce these behaviors. The medial amygdala of mice contains a large population of aromatase neurons and is a critical hub in the social behavior network. Moreover, the neural representation of social stimuli in the medial amygdala displays clear sex differences that track developmental changes in social behaviors. Here, we identify a potential anatomic basis for those sex differences. We found that sensory input from the accessory olfactory bulb (AOB) to aromatase neurons is derived nearly exclusively from the anterior $A O B$, which selectively responds to chemosensory cues from conspecific animals. Through the coordinated use of mouse transgenics and viralbased circuit-tracing strategies, we demonstrate a clear sex difference in the volume of synapses connecting the accessory olfactory bulb to aromatase-expressing neurons in the medial amygdala of male versus female mice. This difference in anatomy likely mediates, at least in part, sex differences in medial amygdala-mediated social behaviors.
\end{abstract}

Key words: accessory olfactory bulb; aromatase; chemical cues; circuitry; medial amygdala; sex difference

\section{Significance Statement}

The medial amygdala is a central hub of the social behavior network of the brain that integrates social information and produces behaviors like aggression, parenting, and reproduction. We determined that in mice, medial amygdala neurons expressing aromatase, an enzyme that converts testosterone to estradiol and plays an important role in establishing neuroanatomical sex differences, receive sensory information from a restricted population of pheromone-sensitive neurons in the vomeronasal pathway. These aromatase-expressing neurons had similar intrinsic electrophysiological properties in both sexes but received more sensory inputs in males than in females. We propose that the different anatomic configurations of social circuits described here contribute to known sex differences in medial amygdala function and, ultimately, to sex differences in critically important social behaviors.

\section{Introduction}

Mice broadcast signals critical for social behavior using semiochemicals that are detected by the vomeronasal organ (VNO) and relayed via the accessory olfactory bulb to the social behavior network (Stowers et al., 2002; Mandiyan et al., 2005). The medial amygdala (MeA) serves as a hub for neural circuits within the social behavior

\footnotetext{
Received November 21, 2019; accepted April 10, 2020; First published May 29, 2020.

The authors declare no competing financial interests.
}

network that identify social cues and guide innate social behaviors (Newman, 1999). These social behaviors are central for an individual's survival and rely on conserved neural circuits (Tinbergen, 1951; Petrovich et al., 2001; Goodson, 2005). MeA-mediated social behaviors including parenting, aggression, mating, and defense are often sexually differentiated (Ferguson et al., 2001; Unger et al.,

Author contributions: A.B., D.A.K., and J.F.B. designed research; A.B., M.H.C., D.A.K., and J.F.B. performed research; A.B., M.H.C., D.A.K., G.-L.L., and J.F.B. analyzed data; A.B., M.H.C., D.A.K., and G.-L.L. wrote the paper. 
2015; Yao et al., 2017), implying that sex differences exist in the configuration and function of the underlying $\mathrm{MeA}$ circuits (Fig. 1; Lehman et al., 1980; Wu et al., 2009). But precisely which features differ in these circuits and how do they produce different patterns of behavior?

We investigated the configuration of aromatase-expressing $\left(\mathrm{arom}^{+}\right)$neurons in the MeA because of their critical role in establishing and maintaining sex differences in social behaviors. We hypothesized that the $\mathrm{arom}^{+}$neurons of MeA would either receive sexually differentiated sensory input or that the intrinsic properties of arom ${ }^{+}$ neurons would be different in male and female mice. Here, we demonstrate that arom ${ }^{+}$neurons of both sexes receive input near exclusively from the anterior division of the accessory olfactory bulb (AOB), with few inputs from the posterior AOB. We also observed no sex difference in the intrinsic electrophysiological function of $\mathrm{arom}^{+}$neurons. However, the synaptic convergence from the AOB to individual arom $^{+}$neurons is substantially greater in males than in females. Together, these data suggest that the volume of synaptic connections made between the $\mathrm{AOB}$ and arom $^{+}$neurons in the MeA provides an anatomic basis for sexually differentiated function in the MeA.

\section{Materials and Methods}

Animals. Forty-four male and female adult mice (1016 weeks old) were group housed in single-sex cages in a temperature-controlled $\left(22^{\circ} \mathrm{C}\right)$ and light-controlled $(12 \mathrm{~h}$ light/dark) facility, with ad libitum access to food and water. All animal procedures were approved by the University of Massachusetts at Amherst Institutional Animal Care and Use Committee and were performed in compliance with all animal care regulations.

The Cyp19a1-Cre transgenic line was generated by BAC (bacterial artificial chromosome) recombination (Yao et al., 2017). A Lox-STOP-Lox-tdTomato reporter line with a LoxP-flanked STOP was used to express tdTomato in $\mathrm{Cre}^{+}$cells (Ai9, The Jackson Laboratory; Madisen et al., 2010). Homozygous Cyp19a1-Cre mice were crossed with homozygous rosa26-IsI-tdTomato reporter mice to visualize aromatase-expressing neurons. The resulting double transgenic mice expressed bright tdTomato fluorescence consistent with past studies investigating

This research was supported by UMass Amherst Start-up Companies (J.F.B.), National Institute of Mental Health (Grant R01-MH-115094; J.F.B.), and a gift from H. Britton Sanderford Jr.

A. Billing's present address: DOT-HUB, Biomedical Optics Research Laboratory, University College London, London WC1E 6BT, UK.

G.-L. Li's present address: Otorhinolaryngology Department, Shanghai Affiliated Eye and ENT Hospital, Fudan University, Shanghai 200433, People's Republic of China.

Acknowledgments: We thank A. Lanjuin and C. Dulac for providing the arom-cre mouse line. We also thank P. Sterling for helpful comments on early drafts of the manuscript.

Correspondence should be addressed to Joseph F. Bergan at jbergan@ umass.edu.

https://doi.org/10.1523/ENEURO.0489-19.2020

Copyright @ 2020 Billing et al.

This is an open-access article distributed under the terms of the Creative Commons Attribution 4.0 International license, which permits unrestricted use, distribution and reproduction in any medium provided that the original work is properly attributed.

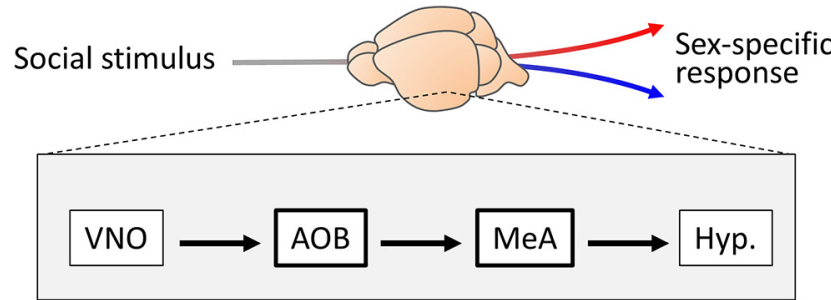

Figure 1. Circuit contributions to sex differences in social behavior. Top, Sex differences in behavior indicate that the same sensory stimulus produces different responses in males and females. Bottom, The vomeronasal system is a critical mediator of social behaviors that often display sex differences. Arrows (bottom) indicate direct anatomic connections between brain regions. Hyp, Hypothalamus.

aromatase expression in the brain. Faithful genetic access to aromatase neurons using this strategy was previously described and verified in the study by Yao et al. (2017).

Slice electrophysiology. Whole-cell patch recordings were made from the posterior dorsal MeA in adult male and adult female (age, 10-16 weeks) mouse brain slices (Fig. 2A). Female mice in the diestrus phase of the estrus cycle were used. Animals were killed the hour before lights-off, and slice recordings were performed during the first $4 \mathrm{~h}$ of the dark phase of the $12 \mathrm{~h}$ light/dark cycle in the vivarium. The arom ${ }^{+}$neurons were distinguished from neurons that did not express aromatase (arom $\left.{ }^{-}\right)$based on the expression of tdTomato in arom ${ }^{+}$neurons. Briefly, targeted expression of tdTomato was achieved in arom ${ }^{+}$ neurons by crossing an aromatase-cre transgenic mouse (Yao et al., 2017) with a tdTomato reporter line (Fig. 2B; Madisen et al., 2010). Fluorescent arom $^{+}$neurons were easily distinguished from arom ${ }^{-}$neurons, and all recorded neurons were filled with neurobiotin for post hoc confirmation of cell type, morphology, and location (Fig. 2C).

Mice were deeply anesthetized with isoflurane and killed. The brain was rapidly removed and placed in icecold (bubbling 95\% $\mathrm{O}_{2} / 5 \% \mathrm{CO}_{2}$ ) solution containing the following: $89.1 \mathrm{~mm}$ sucrose, $13.88 \mathrm{~mm}$ glucose, $87.27 \mathrm{~mm}$ $\mathrm{NaCl}, 25 \mathrm{~mm} \mathrm{NaHCO}_{3}, 2.5 \mathrm{~mm} \mathrm{KCl}, 7 \mathrm{~mm} \mathrm{MgCl} / 6 \mathrm{H}_{2} \mathrm{O}$, $0.37 \mathrm{~mm} \mathrm{CaCl}_{2}$, and $1.25 \mathrm{~mm} \mathrm{NaH}_{2} \mathrm{PO}_{4}$ in $\mathrm{H}_{2} \mathrm{O}$. Coronal slices $(300 \mu \mathrm{m})$ were cut using a vibratome (model VT1200S, Leica) and incubated at $35^{\circ} \mathrm{C}$ for $30 \mathrm{~min}$ in oxygenated artificial CSF (ACSF) containing the following: $127 \mathrm{~mm} \mathrm{NaCl}, 25 \mathrm{~mm}$ glucose, $25 \mathrm{~mm} \mathrm{NaHCO}$, $2.5 \mathrm{~mm}$ $\mathrm{KCl}, 1.325 \mathrm{~mm} \mathrm{MgCl}_{2}, 2.5 \mathrm{~mm} \mathrm{CaCl}$, and $1.2 \mathrm{~mm}$ $\mathrm{NaH}_{2} \mathrm{PO}_{4}$ in $\mathrm{H}_{2} \mathrm{O}$. Slices were then transferred to a recording chamber.

Slices were perfused with oxygenated ACSF and maintained at room temperature for the duration of the recording session. Electrodes were made with borosilicate glass drawn from a vertical pipette extractor (PC-10, Narishige) and were filled with an internal solution $(20 \mathrm{~mm} \mathrm{KCl}, 120$ mм KGlu, 0.1 mм $\mathrm{CaCl}_{2}$, 5 mм EGTA, 5 mм HEPES, 3 mм MgATP, and $0.5 \mathrm{~mm} \mathrm{NaGTP}$, at pH 7.3 osmolarity of 290 mOsm, and impedence of 8-12 M $\Omega$ ). Whole-cell patchclamp recordings were made from arom ${ }^{+}$neurons identified by tdTomato expression and arom $^{-}$neurons in the MeA using infrared differential interference contrast and 
A

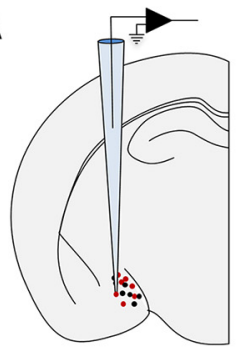

B

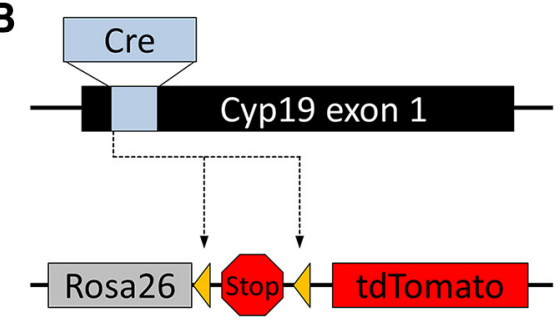

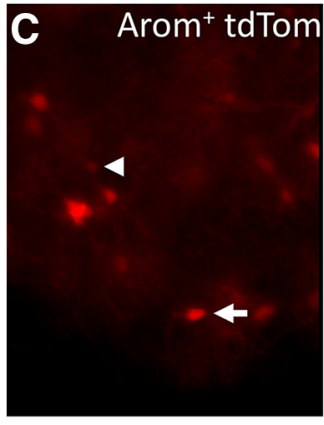

D
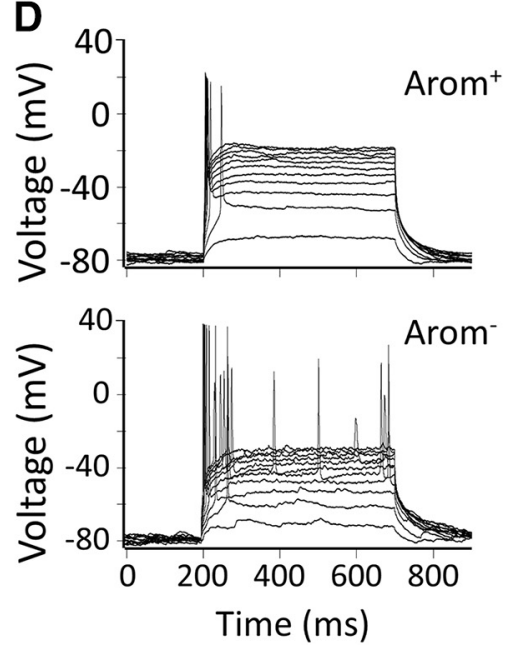

Merge

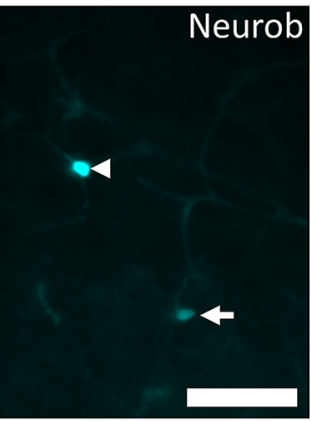

E
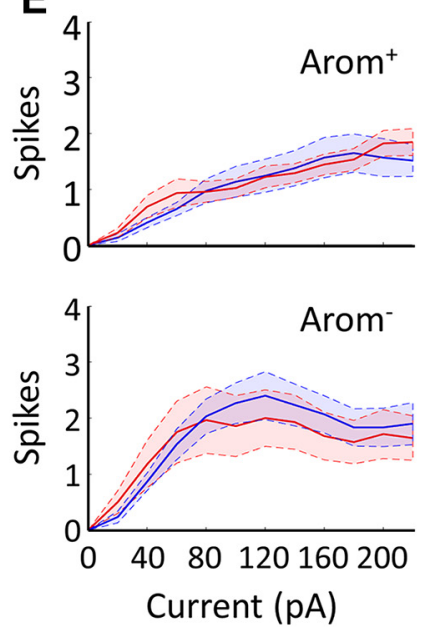

Figure 2. Ex vivo characterization of the intrinsic electrophysiological properties of $\operatorname{arom}^{+}$and arom ${ }^{-}$neurons in males and females. $\boldsymbol{A}$, Schematic of whole-cell patch recording strategy from the MeA of transgenic mice. $\boldsymbol{B}$, Arom ${ }^{+}$neurons were distinguished from arom $^{-}$neurons based on tdTomato expression in a cross between a transgenic mouse line expressing Cre in arom ${ }^{+}$neurons (Yao et al., 2017) and a tdTomato reporter line (Madisen et al., 2010). C, Left, Aromatase-expressing neurons are shown in red. Right, Two recorded neurons filled with neurobiotin-streptavidin are shown in cyan. Middle, Merged channels showing one recorded neuron was arom ${ }^{+}$(arrow) and the other was arom ${ }^{-}$(arrowhead). Scale bar, $250 \mu \mathrm{m}$. D. Firing pattern of a single arom ${ }^{+}$neuron (top) and arom $^{-}$neuron (bottom) in response to current steps ranging from 20 to $220 \mathrm{pA}$. $\boldsymbol{E}$, Average number of spikes are shown for male (blue) and female (red) MeA neurons, with arom ${ }^{+}$neurons (top) and arom ${ }^{-}$neurons (bottom). Shaded areas indicate SEM.

an upright fluorescent microscope (BX51WIF, Olympus) with a $60 \times$ water immersion lens. Neurobiotin $(0.1 \%)$ was added to the internal solution to fill the recorded neurons for subsequent visualization and morphologic analysis.

After achieving whole-cell configuration, voltage was clamped at $-80 \mathrm{mV}$, and a "soft" current-clamp switch was performed in which the current used to hold the cell at $-80 \mathrm{mV}$ was maintained. Neurons were then depolarized by injecting current ranging from 20 to $220 \mathrm{pA}$ in 20 pA steps each for a duration of $500 \mathrm{~ms}$. Recorded voltage signals were filtered and then sampled at $100 \mathrm{kHz}$. The number of action potentials elicited by each current step was recorded for each neuron. The baseline spike rate was determined by injecting no current and recording for $1 \mathrm{~min}$. The threshold for eliciting an action potential was determined by ramping current injection from 0 to 200 pA over a $1 \mathrm{~s}$ epoch; the threshold was determined by the timing of the first spike during this epoch. Measurements were calculated using lgor Pro 6.0 software (WaveMetrics) and MATLAB (MathWorks). Following each recording, brain slices were fixed in PFA for $2 \mathrm{~h}$ at room temperature, washed three times in PBST $(0.1 \%$ Triton X-100 in PBS, pH 8) for $15 \mathrm{~min}$, and incubated in fluorescently conjugated streptavidin (1:200; DyLight 649, Vector Laboratories) to visualize the recorded neurons. After $1 \mathrm{~h}$, sections were washed three times in PBS, 

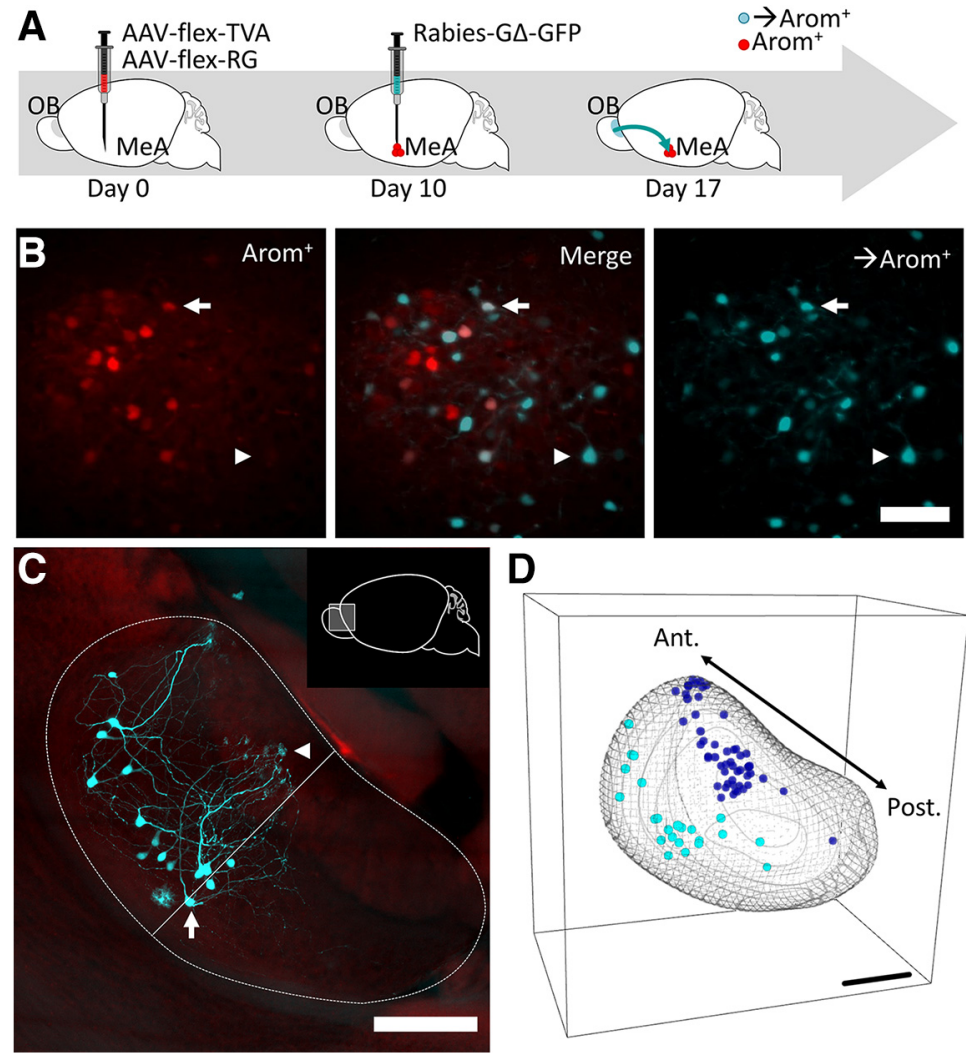

Figure 3. Strategy for circuit mapping from arom ${ }^{+}$neurons in the MeA. $\boldsymbol{A}$, Conditional AAV vectors were used to express TVA, RG, and $\mathrm{mCherry}$ in arom ${ }^{+}$neurons of the MeA (Materials and Methods). After $10 \mathrm{~d}$, G-deleted rabies (GFP) was injected at the same stereotaxic coordinates to infect arom ${ }^{+}$starter neurons, after which $7 \mathrm{~d}$ were allowed for rabies to be transported from arom ${ }^{+}$neurons in the MeA to the AOB. B, Horizontal image of MeA showing arom ${ }^{+}$neurons (red) and arom ${ }^{+} \rightarrow \operatorname{arom}^{+}$) in cyan (arrowhead). Colabeled neurons were interpreted as starter neurons (arrow). $\boldsymbol{C}$, The AOB was rendered transparent and imaged intact. A maximum intensity projection of the entire $\mathrm{AOB}$ showing $\rightarrow \mathrm{arom}^{+}$neurons monosynaptically labeled from the ipsilateral MeA. Arrow, Labeled mitral cell; arrowhead, labeled dendritic arbor in glomerulus; linea alba, thin straight line. $\boldsymbol{D}$, 3D representation of all $\rightarrow$ arom $^{+}$neurons in the AOB in a single animal (cyan, cell bodies; blue, glomeruli). Note the strong anterior bias of both cell bodies and glomeruli. Scale bars, $250 \mu \mathrm{m}$.

mounted on slides, and imaged using a BX51WIF upright fluorescent microscope (Olympus).

Stereotaxic injections. Iontophoretic injections of the anatomic tracer Fluoro-Gold (10\% in double distilled $\mathrm{H}_{2} \mathrm{O}$; fluorochrome) were made in the posterior dorsal MeA of male and female mice (bregma, $-1.8 \mathrm{~mm}$; lateral, $1.8 \mathrm{~mm}$; depth, 4.5-5.5 mm; retaining current, $-1 \mu \mathrm{A}$ constant $\mathrm{DC}$; injection current, $+5 \mu \mathrm{A}$ constant $\mathrm{DC} ; 10 \mathrm{~min})$. Anesthesia was maintained with $1-2 \%$ isoflurane in aseptic conditions throughout the surgery. Good retrograde labeling was observed after a survival period of $7 \mathrm{~d}$. Animals were deeply anesthetized with isoflurane and exsanguinated with $50 \mathrm{ml}$ of cold PBS followed by $25 \mathrm{ml}$ of cold PFA (4\% in PBS). The brain was extracted and postfixed in 4\% PFA at $4^{\circ} \mathrm{C}$ overnight. Fluoro-Gold-labeled tissue samples were sectioned coronally $(100 \mu \mathrm{M})$ and visualized with an ultraviolet excitation filter.

We next used an approach based on a modified rabies virus to identify monosynaptic input specific to the arom ${ }^{+}$ neurons in the MeA (Wickersham et al., 2007; WatabeUchida et al., 2012; Menegas et al., 2015). Briefly, a nonendogenous cell-surface receptor (TVA) required for rabies infection was coexpressed with a rabies envelope glycoprotein $(R G)$ required for replication in $\operatorname{arom}^{+}$neurons of the MeA (Fig. 3A).

All adeno-associated viruses (AAVs) were produced by the UNC Vector Core Facility (Chapel Hill, NC). Rabies circuit tracing experiments involved two consecutive stereotaxic injections in both sexes. In the first injection, $500 \mathrm{nl}$ of AAVFLEX-TVA and AAV-FLEX-RG (both serotype 8; mixed 1:1; Watabe-Uchida et al., 2012) were injected into the posterior dorsal MeA of aromatase-cre mice (bregma, -1.8; lateral, 1.8; depth, 4.5-5.5). After $14 \mathrm{~d}, 300 \mathrm{nl}$ of SAD $\Delta$ G-EGFP(EnvA) virus (Viral Vector Core, Salk Institute, La Jolla, CA) was injected into the MeA at the same stereotaxic coordinates (Wickersham et al., 2007). In two animals, $250 \mathrm{nl}$ of AAVFLEX-TVA (without AAV-FLEX-RG) was injected and, after $14 \mathrm{~d}$, was followed by a $300 \mathrm{nl}$ injection of SAD $\triangle$ G-EGFP (EnvA) virus in the aromatase-cre tdTomato reporter double transgenic line. Excluding AAV-FLEX-RG prevents the synaptic spread of the SAD $\Delta$ G-EGFP(EnvA) virus and allowed us to confirm colocalization of initial rabies infection to cre-expressing (tdTomato-positive) neurons. This is consistent with published reports showing the high genetic specificity of the rabies-based strategy (Wickersham et al., 2007; WatabeUchida et al., 2012; Menegas et al., 2015). 
Table 1: Summary of statistical analyses

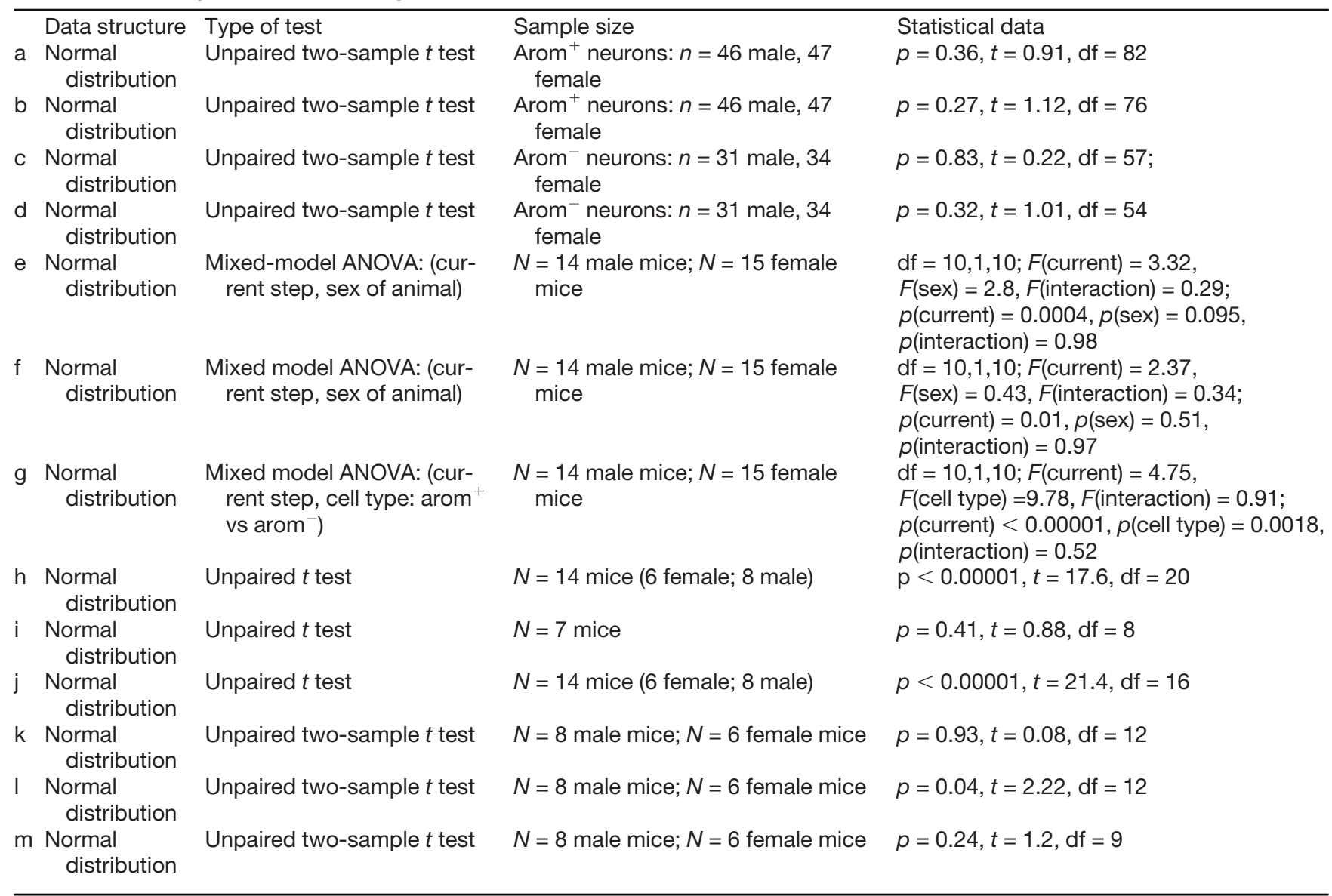

Ten days after the final injection, animals were deeply anesthetized with isoflurane and exsanguinated with 50 $\mathrm{ml}$ of cold PBS followed by $25 \mathrm{ml}$ of cold PFA (4\% in PBS). The brain was extracted and postfixed in $25 \mathrm{ml}$ of hydrogel (recipe: $40 \mathrm{ml}$ of $40 \%$ acrylamide, $10 \mathrm{ml}$ of $2 \%$ bis-acrylamide, $1 \mathrm{~g}$ of VA-044 initiator, $40 \mathrm{ml}$ of $10 \times$ PBS, $100 \mathrm{ml}$ of $16 \%$ PFA, $210 \mathrm{ml}$ of $\mathrm{H}_{2} \mathrm{O}$; Chung et al., 2013) at $4^{\circ} \mathrm{C}$ for $48 \mathrm{~h}$.

After $48 \mathrm{~h}$ of incubation in hydrogel, oxygen was flushed from the hydrogel by bubbling the liquid hydrogel solution with nitrogen. The tissue container was resealed and transferred to a $37^{\circ} \mathrm{C}$ water bath for $1 \mathrm{~h}$. If hydrogel was not yet solidified, the sample was returned to the water bath until polymerization was complete. Excess hydrogel was removed from the brain manually, and the tissue sample was washed in PBST $(0.1 \%$ Triton X-100 in PBS, $\mathrm{pH} 8$ ) overnight at $37^{\circ} \mathrm{C}$ with gentle rocking. The brain was then transferred to clearing solution and passively incubated for $2 \mathrm{~d}$ before active clearing.

Active clearing was performed in a 5 gallon bucket with a custom magnetohydrodynamic (MHD) clearing device (Joseph F. Dwyer, unpublished observations). Briefly, the tissue sample was placed at the intersection of a strong magnetic field and a $0.3 \mathrm{~A}(\sim 30 \mathrm{~V})$ electrical field. The resulting MHD force rapidly removed unbound lipids from the tissue sample and also circulated the clearing solution to keep the sample at a constant temperature. Brains were cleared until bright white and translucent, which typically took $48 \mathrm{~h}$. Brains were then transferred to PBST $(0.1 \%$ Triton X-100, pH 8) for $24 \mathrm{~h}$ with three changes of the PBST solution to help remove the remaining clearing solution. Brains were transferred from PBST to an OptiView imaging solution (Isogai et al., 2017) with a refractive index of 1.45 and incubated at $37^{\circ} \mathrm{C}$ for $2 \mathrm{~d}$ before imaging.

$\mathrm{AOB}$ and MeA images were acquired with the Zeiss Z.1 Lightsheet Microscope (Carl Zeiss). Rabies-labeled GFP ${ }^{+}$ neurons were excited with a $488 \mathrm{~nm}$ laser, and a $561 \mathrm{~nm}$ laser was used to produce an autofluorescence image for subsequent background subtraction and isolation of the GFP signal. Images were collected with a $5 \times$ objective $(\mathrm{MeA})$ or $20 \times$ objective (AOB) with PCO-Edge scMOS cameras (PCO). The MeA was imaged horizontally from the ventral surface of the brain, and the $A O B$ was imaged sagittally from its lateral edge. Images were saved at 1$5 \mu \mathrm{m}$ resolution for cell counting, fiber mapping, and outlining of brain regions. ImageJ was used to format images into .tif stacks.

Data analysis. Statistical analyses and figure generation were done using validated MATLAB scripts (MathWorks). Slice electrophysiology comparisons between two groups were performed with an unpaired $t$ test and a mixedmodel ANOVA for nested comparisons of more than two 
groups. Statistical results were considered significant at $p<0.05$, and ANOVAs returning a significant $p$ value were followed by pairwise comparisons with Bonferroni correction to investigate the significant differences. Cohen's d was calculated by finding the difference of means between each group and dividing by the pooled SD. All means are reported with SE measurements. Regressions were performed in MATLAB using the fit/m and predict functions. All statistical tests are presented in Table 1 along with a more complete description of the statistical results.

\section{Results}

Because aromatase expression is critical to establish sex differences in MeA function, we hypothesized that the intrinsic electrophysiological properties of $\operatorname{arom}^{+} \mathrm{MeA}$ neurons may be different in male and female mice. To test this hypothesis, we measured the electrophysiological properties of arom ${ }^{+}$neurons and arom ${ }^{-}$neurons in brain slices from 14 male and 15 female mice (Fig. 2D; arom $^{+}$ neurons: $n=46$ male, 47 female; arom $^{-}$neurons: $n=65$, 31 male, 34 female). In contrast to our hypothesis, we found no evidence for sex differences in the intrinsic electrophysiological properties of MeA neurons. No sex difference was observed for arom $^{+}$neurons for either input resistance (male, $740 \pm 60 \mathrm{M} \Omega$; female, $670 \pm 40 \mathrm{M} \Omega$; unpaired $t$ test: $p=0.36, t=0.91$, df $=82$; Table 1 , a) or the threshold voltage for eliciting an action potential (male, $-45.9 \pm 1.4 \mathrm{mV}$; female, $-47.9 \pm 0.95 \mathrm{mV}$; unpaired $t$ test: $p=0.27, t=1.12$, df = 76; Table 1, b). Similarly, no sex difference was observed for arom ${ }^{-}$neurons for either input resistance (male, $680 \pm 70 \mathrm{M} \Omega$; female, $700 \pm 70 \mathrm{M} \Omega$; unpaired $t$ test: $p=0.83, t=0.22$, df $=57$; Table 1 , c) or the threshold voltage for eliciting an action potential (male, $-49.4 \pm 1.5 \mathrm{mV}$; female, $-53.4 \pm 1.25 \mathrm{mV}$; unpaired $t$ test: $p=0.32, t=1.01, \mathrm{df}=54$; Table $1, \mathrm{~d})$. In addition, when we measured the number of action potentials elicited by current steps, we observed no significant effect of sex on the number of current-evoked spikes in arom ${ }^{+}$neurons (Fig. $2 E$, top; mixed-model ANOVA: $F=2.8$, df $=1, p=0.10$; Table 1, e; Cohen's $d$ for maximum number of spikes, 0.19 ), or the number of current-evoked spikes in arom $^{-}$neurons of male versus female mice at any current (Fig. 2E, bottom; mixed-model ANOVA: $F=0.43$, df $=1$, $p=0.52$, Table 1, f; Cohen's d for maximum number of spikes, 0.20). However, arom ${ }^{-}$neurons produced more action potentials than arom ${ }^{+}$neurons in response to the same current step (Fig. 2D,E; ANOVA: $F=9.78$, df $=1$, $p=0.002$, Table 1, g). Moreover, the firing rate of arom ${ }^{-}$ neurons increased more steeply with increasing current steps, with a peak firing rate for injected current of $80 \mathrm{pA}$ followed by a gradual reduction in response to larger current steps (Fig. 2E).

Next, we used a modified rabies viral tracing strategy to investigate the configuration of arom $^{+}$neural circuits (Wickersham et al., 2007). Briefly, initial infection was restricted to arom ${ }^{+}$neurons based on cre-dependent expression of the TVA receptor, which is required for EnvA pseudotyped rabies virus to infect mammalian cells, in arom-cre mice. Trans-synaptic spread to neurons that

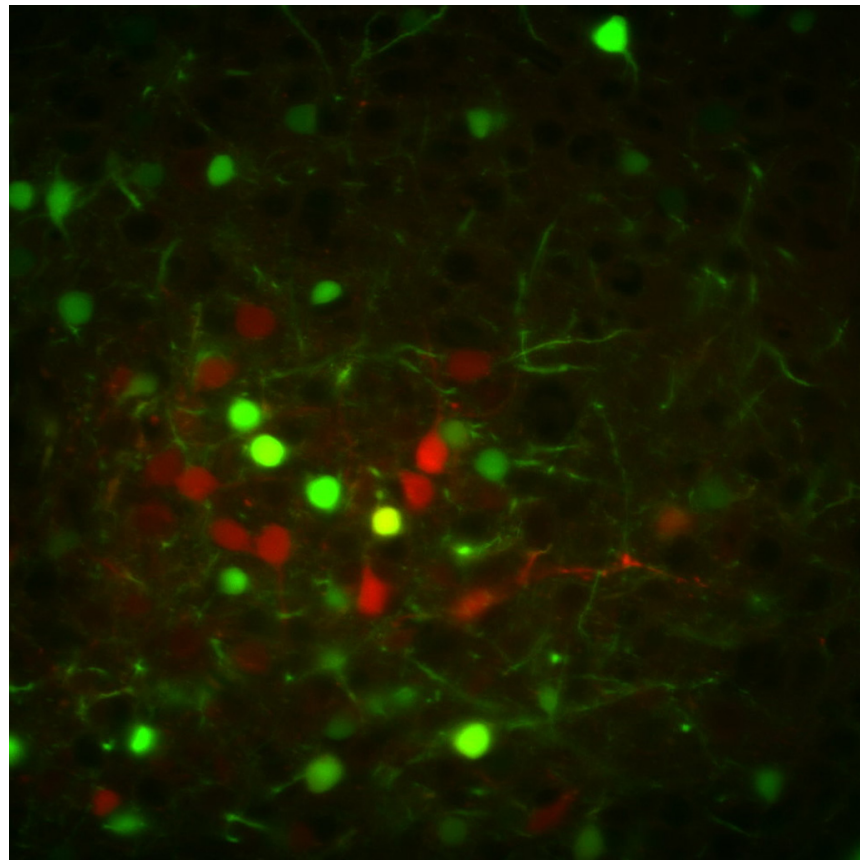

Movie 1. Visualization of viral injection site in the MeA. Horizontal view of the MeA showing tdTomato in $\operatorname{arom}^{+}$neurons (red, aromatase-cre $X$ tdTomato reporter line) and GFP (green) in neurons infected with the modified SAD $\Delta$ G-EGFP (EnvA) rabies virus. Both cell bodies and neural processes are visible. Each new frame represents a movement of $1 \mu \mathrm{m}$ into the brain starting near the ventral surface of the MeA. The field of view was $0.96 \mathrm{~mm}$ in both dimensions. [View online]

contact arom ${ }^{+}$neurons was made possible by also expressing the rabies envelope RG only in arom $^{+}$neurons (Fig. 3A). We identified both local neurons with direct projections to arom ${ }^{+}$neurons (Fig. 3B, Movie 1), as well as long-range input from the $A O B$, which we will abbreviate as $\rightarrow$ arom $^{+}$neurons (Fig. 3C,D, Movie 2). No neurons were labeled in the main olfactory bulb. The $\rightarrow$ arom $^{+}$neurons were located in the mitral/tufted cell layer (Fig. 3C, arrow), and clear dendritic arborizations were visible in $\mathrm{AOB}$ glomeruli of the $\mathrm{AOB}$ (Fig. $3 \mathrm{C}$, arrowhead).

Imaging the intact AOB using CLARITY and lightsheet microscopy (see Materials and Methods) allowed identification of nearly all $\rightarrow$ arom $^{+}$neurons and their corresponding glomeruli (Fig. 3D). The linea alba was used to distinguish the anterior $\mathrm{AOB}$ from the posterior $\mathrm{AOB}$, and the distribution of $\rightarrow$ arom $^{+}$neurons was heavily skewed to the anterior AOB (Fig. 4A; anterior, $89 \pm 2.9 \%$; posterior, $11 \pm 2.9 \%$; unpaired $t$ test: $p<0.00,001, t=17.6$, $\mathrm{df}=20$; Table 1, h). In contrast to the anterior AOB bias observed for rabies-infected arom $^{+}$-projecting neurons, nearly all AOB mitral and tufted cells in both the anterior and posterior AOBs were labeled by the nonconditional retrograde tracer Fluoro-Gold iontophoretically injected in the MeA (Fig. 5; anterior, $51 \pm 2.4 \%$; posterior, $49 \pm$ 2.4\%; unpaired $t$ test: $p=0.41, t=0.88$, df $=8$; Table 1, i). Thus, both anterior and posterior $\mathrm{AOB}$ neurons project to the $\mathrm{MeA}$, but arom ${ }^{+} \mathrm{MeA}$ neurons receive input nearly exclusively from the anterior AOB. 


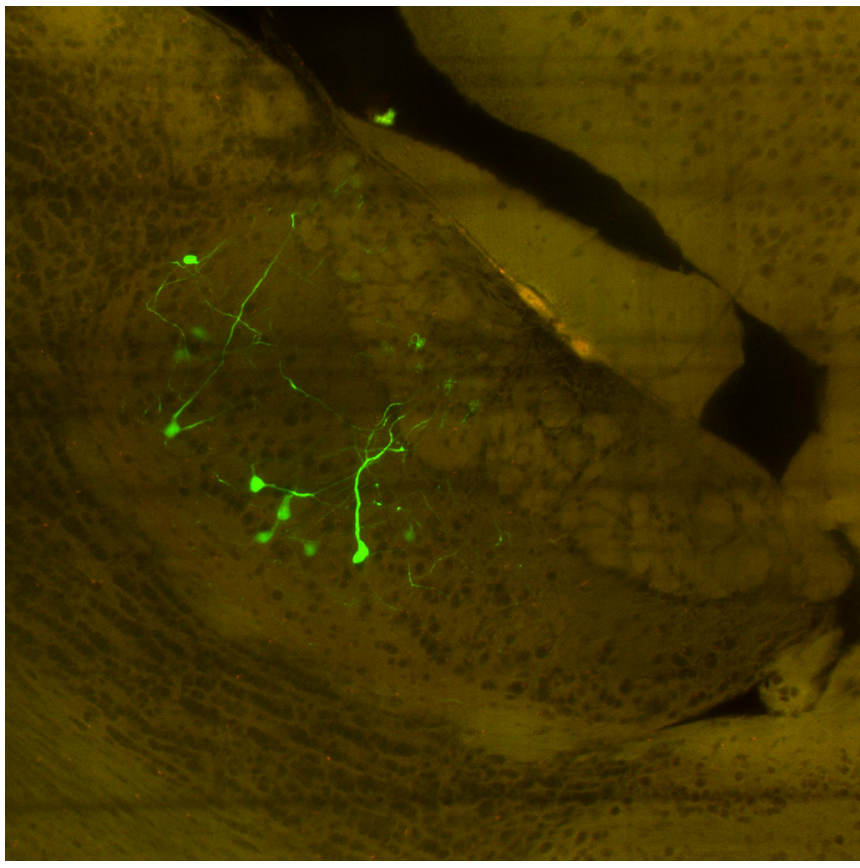

Movie 2. Visualization of rabies-labeled neurons in the $A O B$. Sagittal view of the AOB showing GFP (green) in neurons infected with the modified SAD $\Delta$ G-EGFP(EnvA) rabies virus that project to arom $^{+}$neurons in the MeA. An autofluorescence image was also collected (excitation, $561 \mathrm{~nm}$ ) for improved visualization (red). Cell bodies, neural processes, and dendritic arborization in the AOB glomeruli are visible. Each new frame represents a movement of $1 \mu \mathrm{m}$ into the brain starting near the lateral surface of the AOB and moving medial. Anterior is to the left. The field of view was $1.3 \mathrm{~mm}$ in both dimensions. [View online]

The dendritic arbors of $\rightarrow$ arom $^{+}$neurons in the AOB were traced to the glomeruli they innervated. The $\rightarrow$ arom $^{+}$neurons predominantly innervated anterior AOB glomeruli that receive vomeronasal 1 receptor (V1R)-derived sensory information from the $\mathrm{VNO}$. We imaged the dendritic arbors of $\rightarrow \operatorname{arom}^{+}$AOB neurons, including the innervated glomeruli, in a subset of animals (Fig. 4B,C). The dendrites of each $\rightarrow$ arom $^{+}$neuron in the AOB ramified in 2-10 glomeruli with an average of 4.2 glomeruli innervated per cell. The vast majority of glomerular inputs came from the anterior AOB (Fig. $4 B$; anterior, $85 \pm 1.9 \%$; anterior, $15 \pm 1.9 \%$; unpaired $t$ test: $p<0.00,001, t=21.4$, df $=16$; Table 1, j). Sixty-seven percent of $\rightarrow \operatorname{arom}^{+}$neurons had dendrites that innervated only anterior AOB glomeruli; $30 \%$ of the labeled $A O B$ neurons had dendrites that innervated anterior and posterior $\mathrm{AOB}$ glomeruli; and $3 \%$ of the labeled $A O B$ neurons had dendrites that innervated only posterior AOB glomeruli (Fig. 4D). Thus, the segregation between anterior and posterior $\mathrm{AOBs}$ is not complete; some integration occurs between anterior and posterior glomeruli even within the AOB. Of the AOB neurons receiving input from the posterior glomeruli, $91 \%$ also received input from at least one anterior glomerulus, and most received input from more anterior than posterior glomeruli.

This analysis also revealed a stark sex difference. More $\rightarrow$ arom $^{+}$neurons were labeled by retrograde tracing in
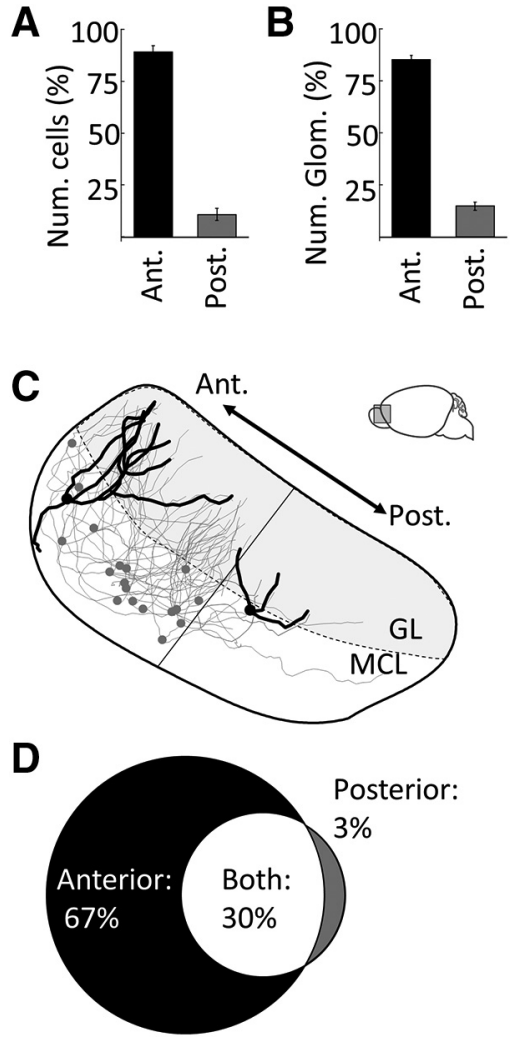

Figure 4. Quantitative analysis of $\mathrm{AOB}$ input to arom $^{+}$neurons in the MeA. $\boldsymbol{A}$, Percentage of $\rightarrow \mathrm{arom}^{+}$neuron cell bodies in the anterior versus posterior AOB. B, Percentage of $\rightarrow \mathrm{arom}^{+}$glomeruli in the anterior versus posterior AOB. $\boldsymbol{C}$, Neuroanatomical reconstruction of the all $\rightarrow$ arom $^{+}$in the $\mathrm{MeA}$ of a single female mouse. Two neurons are highlighted: the first receives input only from anterior glomeruli, while the second, with a markedly smaller dendritic arbor, receives input from only posterior glomeruli (linea alba, thin straight line). $\boldsymbol{D}$, The fraction of $\rightarrow$ arom $^{+}$ neurons that receive input from only the anterior $A O B$ glomeruli (black), from only the posterior AOB glomeruli (gray), or from both the anterior and posterior AOB glomeruli (white). Error bars indicate SEM.

the $\mathrm{AOB}$ of male mice compared with female mice (Fig. 6). In both male and female mice, the number of infected AOB neurons was proportional to the number of arom ${ }^{+}$ "starter neurons" infected in the MeA (Fig. 6C; female regression: $R^{2}=0.80, p=0.016$; male regression: $R^{2}=0.63$, $p=0.018$ ). Because there are a larger number of aromatase neurons in the male MeA (Stanić et al., 2014), one possible explanation of the differential labeling observed in the AOB could be that more arom ${ }^{+}$starter neurons were initially infected in males. While we found a small difference in the numbers of arom ${ }^{+}$starter neurons in the male than in the female MeA, this difference was not statistically significant (male, $56.6 \pm 11.2 \mathrm{MeA}$ cells; female, $54.5 \pm 14.3 \mathrm{MeA}$ cells; unpaired $t$ test: $p=0.93, t=0.08$, $\mathrm{df}=12$; Table $1, \mathrm{k}$ ).

To further rule out the possibility that the larger number of neurons labeled in the AOB of males was due to slight differences in the numbers of starter neurons, we normalized the number of labeled $A O B$ projection neurons by 
A

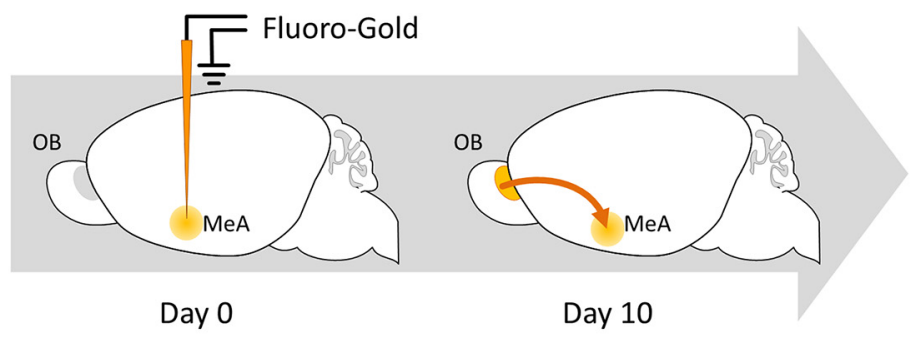

Day 0

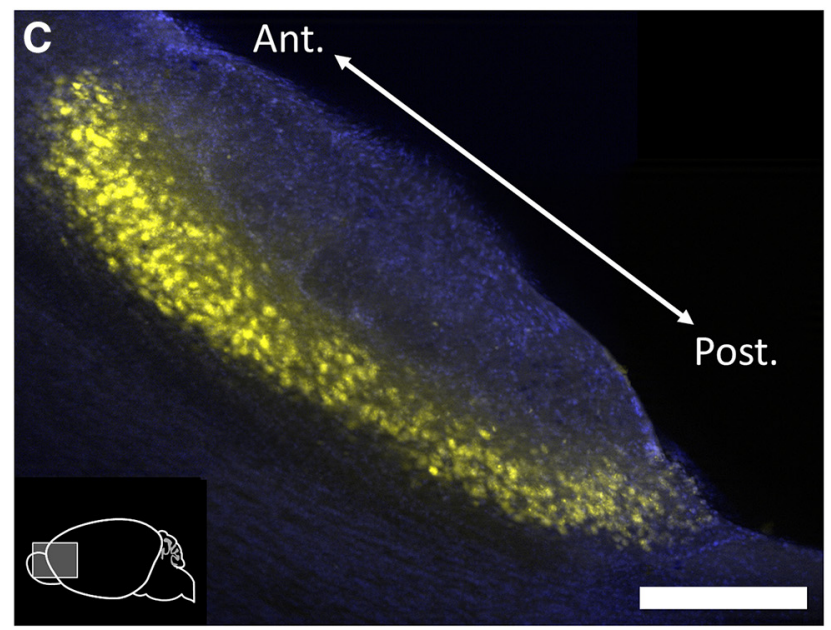

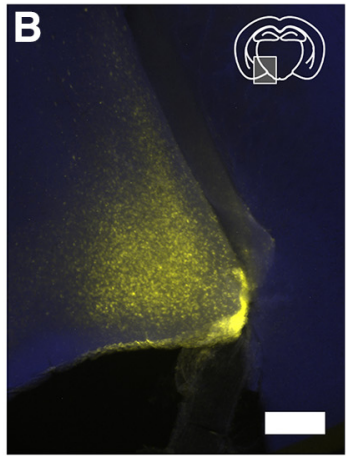

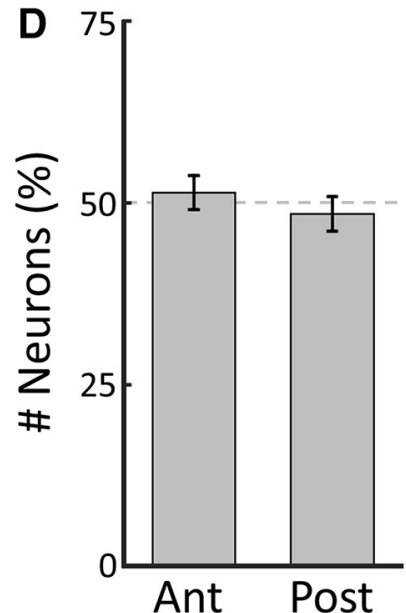

Figure 5. Classical retrograde tracing from the MeA to the AOB. $\boldsymbol{A}$, Fluoro-Gold was iontophoretically injected into the MeA, and $10 \mathrm{~d}$ were allowed for retrograde transport of Fluoro-Gold from the MeA to the AOB. B, A Fluoro-Gold injection site demonstrates labeling in both the dorsal and ventral MeA. $\boldsymbol{C}$, Retrogradely labeled projection neurons in the AOB mitral cell layer showing dense labeling in both the anterior and posterior AOB. $\boldsymbol{D}$, Percentage of neurons located in the anterior versus posterior AOB. Scale bars, $250 \mu \mathrm{m}$.

dividing by the number of starter neurons in the MeA of each animal (Fig. 6B). The stronger labeling in the male $A O B$ remained significant after accounting for differences in the number of starter neurons in each animal (male, $1.25 \pm 0.43 \mathrm{AOB}$ cells/MeA cell; female, $0.13 \pm 0.05 \mathrm{AOB}$ cells $/ \mathrm{MeA}$ cell; unpaired $t$ test: $p=$ $0.04, t=2.22, \mathrm{df}=12$; Table 1, I). Comparing the pattern of connectivity between the AOB and $\mathrm{MeA}$ arom ${ }^{+}$neurons in male and female mice revealed a similar anterior bias in both sexes, with the vast majority of labeled neurons located in the anterior AOB (anterior cells in males, $86.068 \pm 4.0 \%$; anterior cells in females, $93.9 \pm 3.3 \%$; , unpaired $t$ test: $p=0.24, t=1.2$, df $=9$, Table 1, m). A regression analysis comparing the rate of $A O B$ infection for the number of starter neurons infected in males and females showed a larger slope for males than females, with the $95 \%$ confidence intervals for predicted $\mathrm{AOB}$ neurons separated for $\mathrm{MeA}$ infection rates $>50$ starter neurons in a given $100 \mu \mathrm{m}$ slice. Therefore, we found that each arom ${ }^{+}$neuron in the male $\mathrm{MeA}$ receives input from nearly an order of magnitude more $A O B$ neurons on average-indicating a robust sexual difference in the connectivity between the anterior $\mathrm{AOB}$ and aromatase-expressing neurons in the MeA (Fig. 6C).

\section{Discussion}

Here, we show that in both male and female mice, a set of neurons in the $\mathrm{AOB}$ projects directly to $\mathrm{arom}^{+}$neurons in the MeA. Approximately $90 \%$ of $A O B$ input to arom ${ }^{+}$ neurons is from the anterior $\mathrm{AOB}$ and $10 \%$ is from the posterior $\mathrm{AOB}$, and essentially no direct input is from the main olfactory bulb. The topographical segregation of V1R-derived and vomeronasal 2 receptor (V2R)-derived information established in the VNO is maintained in the $A O B$, as V1R-expressing sensory neurons project to the anterior $\mathrm{AOB}$ and V2R-expressing sensory neurons project to the posterior AOB (Dulac and Torello, 2003). It is possible that the enhancement of anterior $A O B$ neurons projecting to arom ${ }^{+}$neurons in the MeA may also reflect the topographic distribution of arom ${ }^{+}$neurons in the posterodorsal MeA. Because arom ${ }^{+} \mathrm{MeA}$ neurons receive input almost exclusively from the anterior AOB (V1R), our study demonstrates that the separation of V1R-derived from V2R-derived sensory channels is maintained at least to the level of the MeA. Consistent with these findings, behaviors mediated by arom ${ }^{+} \mathrm{MeA}$ neurons (Unger et al., 2015; Yao et al., 2017) are likely driven by sensory cues detected by V1R receptors. V1R receptors respond to lipophilic odorants, including sulfated steroids, that convey information about the physiological status of conspecific 


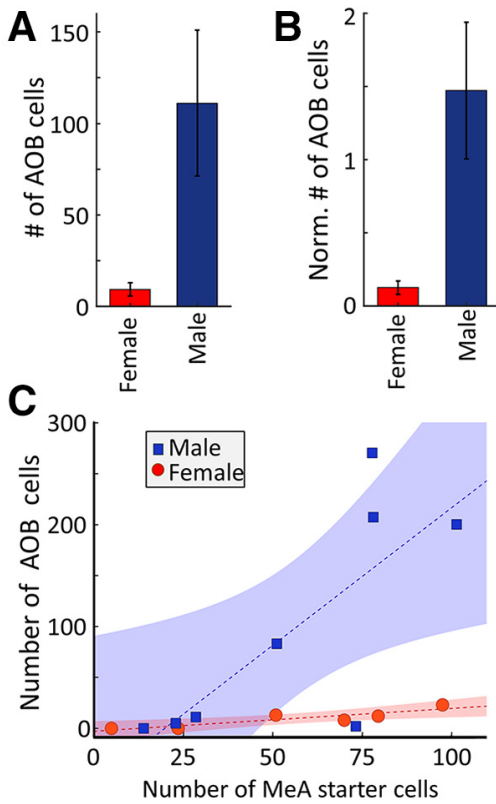

Figure 6. Sex differences in the AOB projection to arom ${ }^{+} \mathrm{MeA}$ neurons. $\boldsymbol{A}$, The average number of $\mathrm{arom}^{+}$projecting AOB neurons in female (red) or male (blue) mice. $\boldsymbol{B}$, Average number of arom $^{+}$projecting AOB neurons in female (red) or male (blue) mice after normalization by the number of starter neurons in the MeA. $\boldsymbol{C}$, Relationship between the numbers of $\operatorname{arom}^{+}$starter neurons in the $\mathrm{MeA}$ and $\rightarrow$ arom $^{+}$neurons in the AOB of male (blue squares) and female (red circles) mice. Dashed lines indicate the best linear fit to the data, and the shaded regions indicate the $95 \%$ confidence interval on each fit. Error bars indicate SEM. individuals (Nodari et al., 2008; Isogai et al., 2011; Hammen et al., 2014), indicating that arom $^{+}$neurons have direct access to sensory channels strongly linked to sexually differentiated behaviors (Nodari et al., 2008; Isogai et al., 2011).

While the sensory stimuli and neuroendocrine states that drive sex differences in social behaviors have been established for some time, the circuit mechanisms that produce sex differences in behavior are less well understood. Initially, we hypothesized that differences in the intrinsic properties of $\mathrm{arom}^{+}$neurons may produce sex differences in circuit functions (Cooke et al., 1999). This line of reasoning was based on the critical role for aromatase in the development and maintenance of hormonedependent sex differences in MeA neuroanatomy (Cooke et al., 1999; Morris et al., 2008; Wu et al., 2009; Bergan et al., 2014). While we were able to establish that arom ${ }^{+}$ neurons represent an electrophysiologically distinct category of MeA neuron (Keshavarzi et al., 2014), we observed no obvious sex differences in the intrinsic properties of either the arom ${ }^{+}$or arom ${ }^{-}$neurons. The lack of clear sex differences in arom $^{+}$neurons in this region is, at first pass, surprising given known sex differences in anatomy, sensory representation, and contributions to the behavior of MeA neurons (Cooke et al., 1999; Morris et al., 2008; Wu et al., 2009; Bergan et al., 2014; Hong et al., 2014; Unger et al., 2015; Yao et al., 2017).

Our anatomic results demonstrate that some arom ${ }^{+}$ neurons receive input from the anterior $\mathrm{AOB}$, however, the percentage of $\mathrm{MeA}$ arom+ neurons that receive $A O B$ input is not yet known. Our electrophysiological
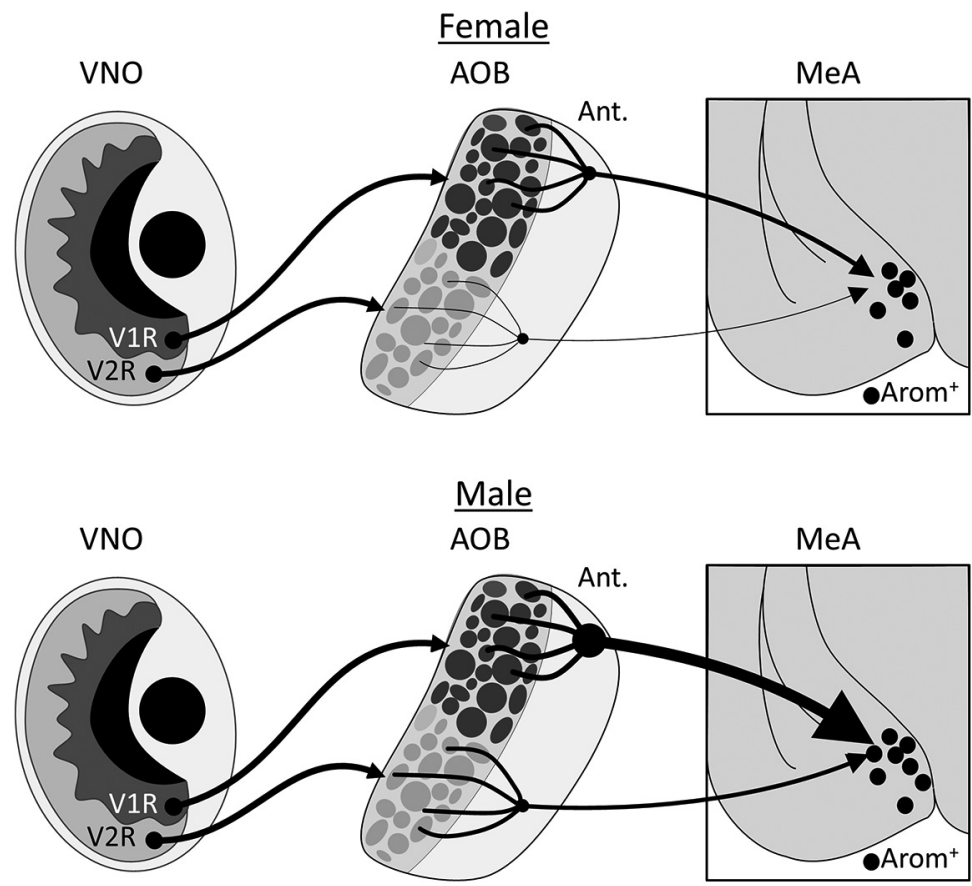

Figure 7. Diagram of $A O B$ inputs to arom ${ }^{+} \mathrm{MeA}$ neurons in male and female mice. V1R-expressing sensory neurons project from the VNO to the anterior $\mathrm{AOB}$ in both male and female mice, while V2R-expressing sensory neurons project to the posterior AOB. Mitral cells in the anterior AOB provide $\sim 90 \%$ of the input to arom ${ }^{+}$neurons in the MeA, with the remaining $10 \%$ coming from the posterior AOB. This ratio is similar between male and female mice. The male MeA contains more aromatase neurons than the female $\mathrm{MeA}$, each of which receives more input from the anterior AOB. 
experiments could not distinguish arom + MeA neurons based on whether they did or did not receive AOB input and may have missed a subtle difference in a relevant subpopulation. Moreover, our electrophysiological data cannot rule out all potential sex differences in electrophysiological function of MeA neurons. For example, it is possible that the different hormonal milieus present in adult males and females, including those linked to estrus state, may induce differences in electrophysiological function that are not captured by the ex vivo slice preparation we used (Cooke et al., 1999; Woolley, 1999).

Sex differences in neural processing exist at many points along the trajectory from sensory transduction to motor output. Some moths express different receptors at the sensory epithelium of male and female animals (Schneiderman et al., 1986). Fruit flies display few sex differences at the sensory epithelium, but second-order projection neurons route sex-specific sensory information to different targets in the brains of male and female flies (Ryner et al., 1996; Ruta et al., 2010; Kohl et al., 2013). Similarly, we found that the second-order projection from AOB neurons to arom ${ }^{+}$neurons in the MeA displays a large sex difference in mice (Fig. 7). The larger number of $A O B$ neurons labeled in the male AOB cannot be explained by the larger number of arom $^{+}$neurons in the male MeA (Cooke et al., 1999) as only slightly more arom $^{+}$ $\mathrm{MeA}$ starter neurons were infected in male mice. Moreover, the sex difference in $\mathrm{AOB}$ neurons projecting to arom ${ }^{+} \mathrm{MeA}$ neurons persists even after normalizing by the size of the initial MeA infection. Therefore, the projection of $\rightarrow \mathrm{arom}^{+}$neurons to the MeA of mice is configured differently in male and female mice.

The functional consequences of the anatomic sex difference described here are difficult to predict. It is possible that $A O B$ input to arom $^{+} \mathrm{MeA}$ neurons of male animals is simply stronger, with greater numbers of synaptic contacts. Another possibility is that there is less branching of $A O B$ neurons in males and, accordingly, males require integration from a larger number of $A O B$ neurons to innervate the same percentage of $\mathrm{MeA}$ arom ${ }^{+}$ neurons. Indeed, each individual $A O B$ synapse with an $\mathrm{arom}^{+} \mathrm{MeA}$ neuron may be weaker in male versus female mice. Moreover, while both male mice and female mice receive input from the anterior $A O B$, it is possible that the subset of $\mathrm{V} 1 \mathrm{R}$ receptors providing sensory input is different in male versus female mice. Despite these outstanding questions, our results unambiguously show that the projection from $\mathrm{AOB}$ neurons to arom ${ }^{+} \mathrm{MeA}$ neurons is configured differently in male versus female mice.

\section{References}

Bergan JF, Ben-shaul Y, Dulac C (2014) Sex-specific processing of social cues in the medial amygdala. Elife 3:e02743.

Chung K, Wallace J, Kim S-Y, Kalyanasundaram S, Andalman AS, Davidson TJ, Mirzabekov JJ, Zalocusky KA, Mattis J, Denisin AK, Pak S, Bernstein H, Ramakrishnan C, Grosenick L, Gradinaru V, Deisseroth K (2013) Structural and molecular interrogation of intact biological systems. Nature 497:332-337.

Cooke BM, Tabibnia G, Breedlove SM (1999) A brain sexual dimorphism controlled by adult circulating androgens. Proc Natl Acad Sci U S A 96:7538-7540.
Dulac C, Torello AT (2003) Molecular detection of pheromone signals in mammals: from genes to behaviour. Nat Rev Neurosci 4:551-562.

Ferguson JN, Aldag JM, Insel TR, Young LJ (2001) Oxytocin in the medial amygdala is essential for social recognition in the mouse. $J$ Neurosci 21:8278-8285.

Goodson JL (2005) The vertebrate social behavior network: evolutionary themes and variations. Horm Behav 48:11-22.

Hammen GF, Turaga D, Holy TE, Meeks JP (2014) Functional organization of glomerular maps in the mouse accessory olfactory bulb. Nat Neurosci 17:953-961.

Hong W, Kim DW, Anderson DJ (2014) Antagonistic control of social vs repetitive self-grooming behaviors by separable amygdala neuronal subsets. Cell 158:1348-1361.

Isogai Y, Si S, Pont-Lezica L, Tan T, Kapoor V, Murthy VN, Dulac C (2011) Molecular organization of vomeronasal chemoreception. Nature 478:241-245.

Isogai Y, Richardson D, Dulac C, Bergan JF (2017) Optimized protocol for imaging cleared neural issues using light microscopy. In: Synapse development, methods and protocols. (Poulopoulos A, ed), pp 137-153. New York: Springer.

Keshavarzi S, Sullivan RKP, Ianno DJ, Sah P (2014) Functional properties and projections of neurons in the medial amygdala. $J$ Neurosci 34:8699-8715.

Kohl J, Ostrovsky AD, Frechter S, Jefferis GS (2013) A bidirectional circuit switch reroutes pheromone signals in male and female brains. Cell 155:1610-1623.

Lehman MN, Winans SS, Powers JB (1980) Medial nucleus of the amygdala mediates chemosensory control of male hamster sexual behavior. Science 210:557-560.

Madisen L, Zwingman TA, Sunkin SM, Oh SW, Zariwala HA, Gu H, Ng LL, Palmiter RD, Hawrylycz MJ, Jones AR, Lein ES, Zeng H (2010) A robust and high-throughput Cre reporting and characterization system for the whole mouse brain. Nat Neurosci 13:133-140.

Mandiyan VS, Coats JK, Shah NM (2005) Deficits in sexual and aggressive behaviors in Cnga2 mutant mice. Nat Neurosci 8:16601662.

Menegas W, Bergan JF, Ogawa SK, Isogai Y, Umadevi Venkataraju K, Osten P, Uchida N, Watabe-Uchida M (2015) Dopamine neurons projecting to the posterior striatum form an anatomically distinct subclass. Elife 4:e10032.

Morris JA, Jordan C, Breedlove SM (2008) Sexual dimorphism in neuronal number of the posterodorsal medial amygdala is independent of circulating androgens and regional volume in adult rats. J Comp Neurol 506:851-859.

Newman SW (1999) The medial extended amygdala in male reproductive behavior: a node in the mammalian social behavior network. Ann N Y Acad Sci 877:242-257.

Nodari F, Hsu FF, Fu X, Holekamp TF, Kao LF, Turk J, Holy TE (2008) Sulfated steroids as natural ligands of mouse pheromone-sensing neurons. J Neurosci 28:6407-6418.

Petrovich GD, Canteras NS, Swanson LW (2001) Combinatorial amygdalar inputs to hippocampal domains and hypothalamic behavior systems. Brain Res Brain Res Rev 38:247-289.

Ryner LC, Goodwin SF, Castrillon DH, Anand A, Villella A, Baker BS, Hall JC, Taylor BJ, Wasserman SA (1996) Control of male sexual behavior and sexual orientation in Drosophila by the fruitless gene. Cell 87:1079-1089.

Ruta V, Datta SR, Vasconcelos ML, Freeland J, Looger LL, Axel R (2010) A dimorphic pheromone circuit in Drosophila from sensory input to descending output. Nature 468:686-690.

Schneiderman AM, Hildebrand JG, Brennan MM, Tumlinson JH (1986) Trans-sexually grafted antennae alter pheromone-directed behaviour in a moth. Nature 323:801-803.

Stanić D, Dubois S, Chua HK, Tonge B, Rinehart N, Horne MK, Boon WC (2014) Characterization of aromatase expression in the adult male and female mouse brain: I. Coexistence with oestrogen receptors $\alpha$ and $\beta$, and androgen receptors. PLoS One 9:e90451.

Stowers L, Holy TE, Meister M, Dulac C, Koentges G (2002) Loss of sex discrimination and male-male aggression in mice deficient for TRP2. Science 295:1493-1500. 
Tinbergen N (1951) The study of instinct. New York: Oxford UP.

Unger EK, Burke KJ Jr, Yang CF, Bender KJ, Fuller PM, Shah NM (2015) Medial amygdalar aromatase neurons regulate aggression in both sexes. Cell Rep 10:453-462.

Watabe-Uchida M, Zhu L, Ogawa SK, Vamanrao A, Uchida N (2012) Whole-brain mapping of direct inputs to midbrain dopamine neurons. Neuron 74:858-873.

Wickersham IR, Lyon DC, Barnard RJ, Mori T, Finke S, Conzelmann KK, Young JA, Callaway EM (2007) Monosynaptic restriction of transsynaptic tracing from single, genetically targeted neurons. Neuron 53:639-647.

Woolley CS (1999) Electrophysiological and cellular effects of estrogen on neuronal function. Crit Rev Neurobiol 13:1-20.

Wu MV, Manoli DS, Fraser EJ, Coats JK, Tollkuhn J, Honda S, Harada N, Shah NM (2009) Estrogen masculinizes neural pathways and sex-specific behaviors. Cell 139:61-72.

Yao S, Bergan J, Lanjuin A, Dulac C (2017) Oxytocin signaling in the medial amygdala is required for sex discrimination of social cues. Elife 6:e31373. 